Vol.15, No. 57, 2020, 1199-1212

\title{
EFFECT OF PCM INTEGRATION AT DIFFERENT HEIGHTS OF REFRIGERATOR CABINET
}

\author{
Moataz M. Raouf ${ }^{1}$, M. G. Mousa ${ }^{2}$, O. Abdelrehim ${ }^{2}$, and E. A. Abdel-Hadi ${ }^{3}$ \\ ${ }^{1}$ Mechanical Engineering Department, The Higher Technological Institute, $10^{\text {th }}$ \\ of Ramadan City, Egypt. \\ ${ }^{2}$ Mechanical Power Engineering Department, Faculty of Engineering, Mansoura University, \\ El-Mansoura, Egypt. \\ ${ }^{3}$ Mechanical Engineering, Banha University, Shubhra, Egypt. \\ ${ }^{*}$ Corresponding author address: moataz.raouf@hti.edu.eg.
}

\begin{abstract}
:
In this study, a refrigeration system developed by phase change material, PCM, is compared to a conventional refrigerator. Equal thermal loads (i.e. water) are gripped by the evaporator cabinet at different height levels apart from the evaporator surface. In the modified refrigerator, different PCMs are attached to the bottom side of the stored products. Then a comparison between products of the conventional and modified refrigerator is held using multiple parameters such as: minimum approachable temperature and temperature fluctuation during cyclic operation. While, period factor and heat recovery gained are investigated at planned power outage intervals. The

01 involved PCMs types are (i.e. C-18, RT-9, cooler shock) while paring both of (RT-9 and $\mathrm{C}-18$ ) is developed. Tests performed at different heights with the lower evaporator surface as the reference point show that RT-9 PCM achieves the maximum net energy saving ratios of $23 \%$ at dimensionless heights of $\mathrm{H}=0.25$ and $25 \%$ at $\mathrm{H}=0.375$.
\end{abstract}

KEYWORDS: Thermal Storage, Phase Change Materials, Domestic Refrigerator, Power Outage, Period Factor, and Energy saving.

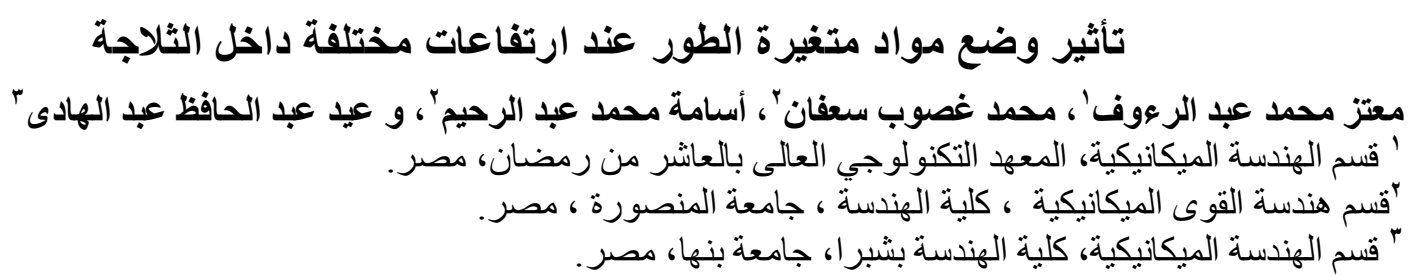

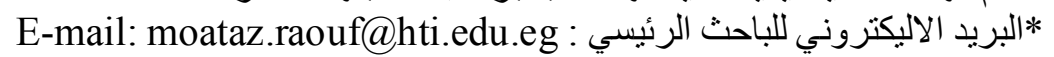

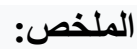

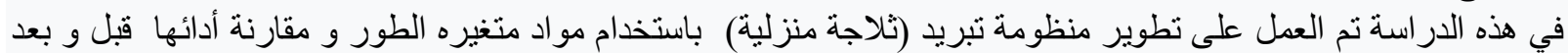

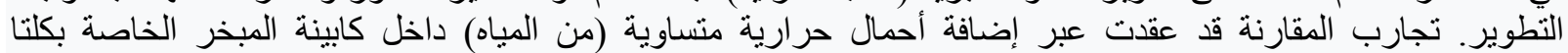


المنظومتين. تم إرفاق أنواع مختلفة من المواد متغيره الطور أسفل المنتجات المجمدة بهدف تخزين الطائ الطاقة الحرارية الكامنة

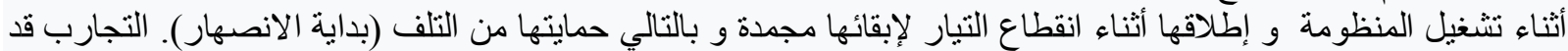

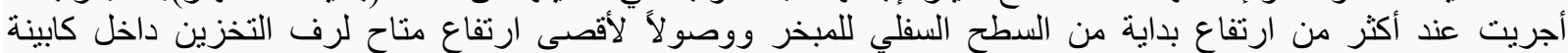

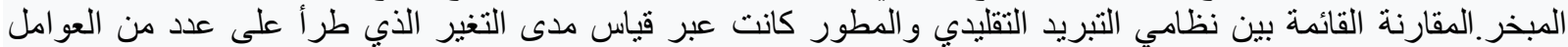

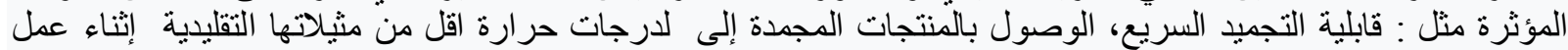

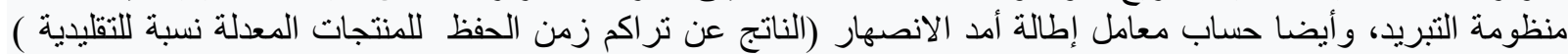

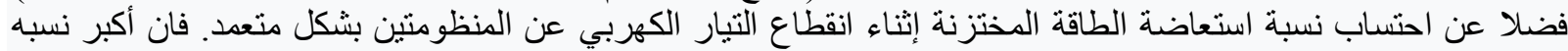

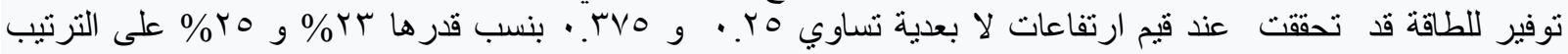

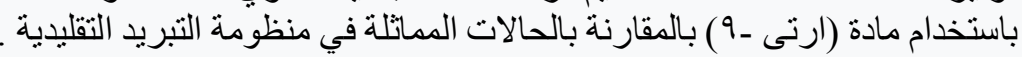

الكلمات المفتاحية : خزان حرارة ، مواد متغيرة الطور،الثلاجات المنزلية،غياب التيار الكهربي، معامل الزمن، و توفير الطاقة.

\section{INTRODUCTION AND LITERATURE REVIEW}

The extensive energy demand urged numerous researchers to give their contributions not only to the development of energy production, transmission and distribution but also towards energy consumption and storage (Bansal, Vineyard and Abdelaziz, 2011). Thermal heat storage materials are frequently known as phase change materials (PCMs) are involved in various applications like (Food Transportation, Automobiles, Construction materials, Electronics, House heating, Catering.... etc.) (Sarbu and Dorca, 2019). The fulfillments of PCM integration and its effective parameters on PCM performance are considered researchers' main concerns in refrigeration systems for either heat (at condenser) or cold storage (at evaporator and compartment) (Mastani Joybari et al., 2015). Integrating solid state pcm to the hot walled condenser of domestic refrigerator resulted in limited compartment temperature because of the incremented evaporator pressure (Cheng and Yuan, 2013). A degraded performance is acquired far from the phase change temperature (Cheng et al., 2011).Also, Assigning of PCM pouches very close to a free convection condenser (i.e. at the back wall of the refrigeration) reveals a reduction in power consumption by $10 \%$ value of the coefficient of performance (C.O.P) confined to the phase change temperature and room conditions (Pirvaram, Sadrameli and Abdolmaleki, 2019). The conditioned enhancements of applying PCM at condenser side may explain the minimized attention for such configurations (Maiorino et al., 2019). Most of Evaporator side research papers (including compartment) can be divided based on investigation points including the state change temperature, PCM slab thickness, its design, location, and the impact of thermal load (i.e. Power outage, Compartment load, Evaporation temperature...etc.)(Rostami et al., 2020). Evaporation in domestic refrigerators is depends on one of free or forced convective heat transfer. Certain studies mentioned that the exposure of PCM to a naturally cooled evaporator is more rewarding (Elarem et al., 2017).

The leading purpose of that, is the proven heat transfer rate from the evaporator, Moreover, PCM can reserve extra cooling capacity of the system (Visek et al., 2014). As well as, resulting in larger evaporator temperature and pressure during phase change period of PCM (Rahman, 2013). As a result of incorporating PCM(s), the compressor needs to work for a longer time period to charge the energy storage. Nevertheless, despite longer compressor ON time in each cycle to charge PCM, the global ON-time ratio decreases due to longer compressor OFF time (LópezSabirón et al., 2014). Main advantages of longer compressor OFF duration are lower overall energy consumption, better food quality, and normal compressor start/stop operation (BenAbdallah et al., 2019). Furthermore, PCM is presumably helpful in power cutoffs since it controls temperature incremental rate of air and product throughout power failure (E. Oró et al., 2012). Besides, a sustained compartment temperature is approached by PCM engagement (Eduard Oró et al., 2012). Nonetheless, when the evaporator is immersed in a PCM has a sate change temperature higher than the compartment thermostat set-temperature, accumulated 
thermal resistance is occurred at evaporator boundaries which, consequently, resulted in more frequent compressor start/stop (Azzouz, Leducq and Gobin, 2009).

Depending on the former review, the thermal inertia of PCM integration is found to be more helpful in the refrigerator compartment despite of the downsides of its utilization in contact with the evaporator surface (i.e. thermal resistance). The dedication of reliably proven commercial PCMs to the preserved products rather than the compartments is needed to be examined at different locations inside the evaporator Cabinet. Also, the influence of PCM integration on the stored frozen product temperature achieved and fluctuations during cyclic operation is to be analyzed during cyclic operation. While, the energy saving capabilities resulted from the delaying of the products under-thawing time after planned power outage is to be stated.

\section{EXPERIMENTAL TEST RIG}

The experimental test rig comprises a single door domestic refrigerator, Fig. 1a, based on a simple vapor compression cycle with technical specifications listed in tablel.

The test section unit of the modified refrigerator consists of an evaporator cabinet, water pan, and various PCM mate (i.e. pouch), Fig. $1 \mathrm{~b}$.

Table1. Technical data of the Refrigerator

Table2. Physical data of Single PCMs

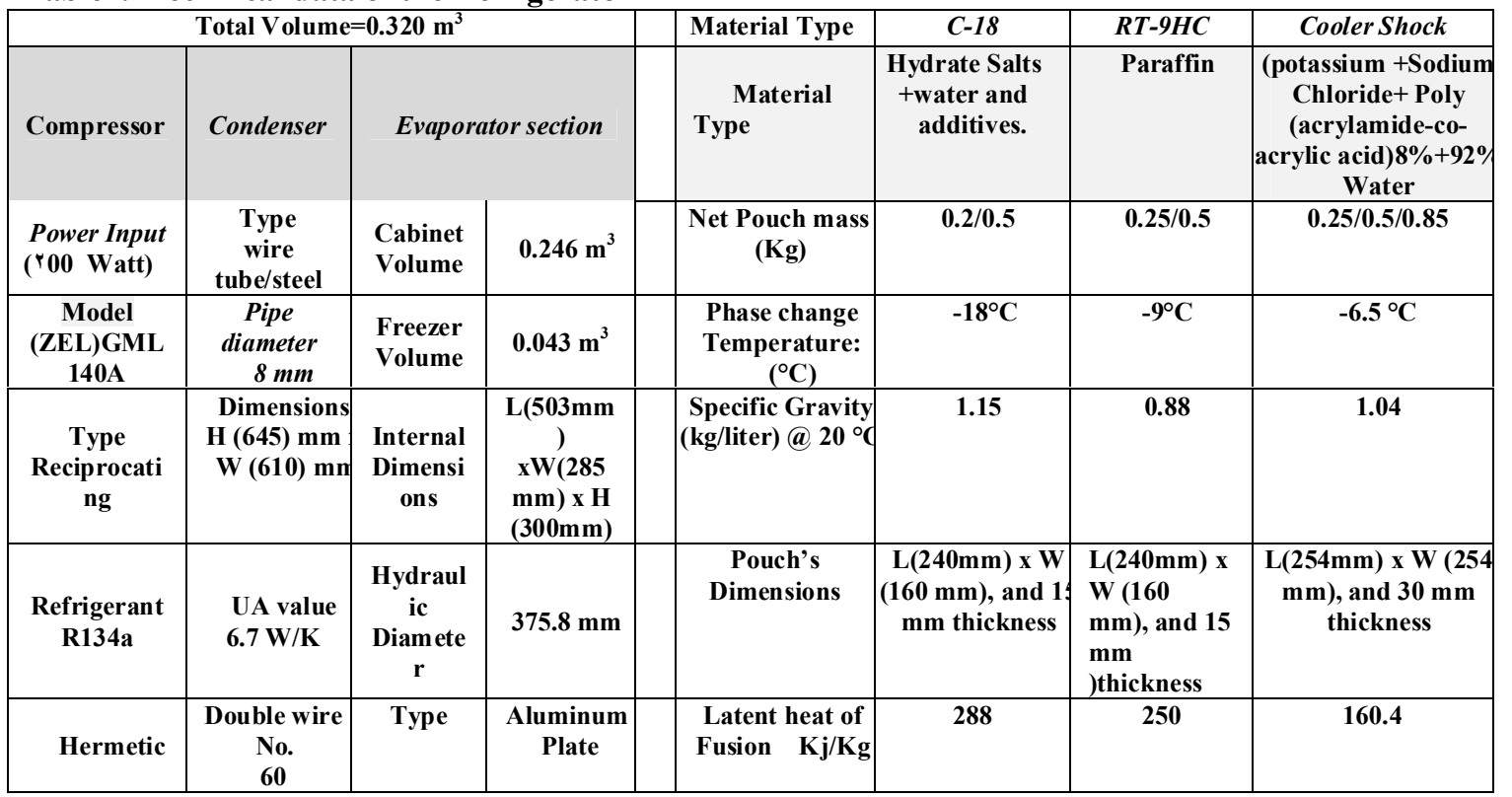

The water pan has outer dimensions of $210 \mathrm{~mm} \times 150 \mathrm{~mm} \times 100 \mathrm{~mm}$, as, placed on the top of the Water mass of $1.0 \mathrm{~kg}$ occupies the water pan as a sample of refrigerator thermal load. A group of PCMs are implemented in the present experimental work; (i) salt hydrate-based PCM , known as Climsel C-18 (www.climator.com/en/pcm-climsel), (ii) paraffin, a pure organic material with a brand name of RT-9 (https://www.rubitherm.eu/), and (iii) eutectic mixture (potassium salt + Sodium Chloride+ Poly (acrylamide-co-acrylic acid)) $8 \%+92 \%$ Water), known as Cooler shock. The primary data provided by the manufacturers of the PCMs are listed in table 2 .

\subsection{Experimental procedures}

In the conducted Experiments, tests initiation is at a repeated time zone and is preconditioned by maintaining refrigerator components at room temperature. The following procedures were held up for every single test: 
1- Check all the mounted energy and temperature sensors.

2- Measure PCM pouches mass and then the mass and volume of thermal load (i.e. water).

3- Adjust the level grid shelf by the height stand.

4- Mount three thermistors on PCM pouches and then insert six thermistors inside the water pan.

5- Adjust the thermostat then check the air leakage through door gaskets by light test.

6- Turn on data acquisition system software's then run on the voltage stabilizer.

7- Monitor the cyclic operation for $24 \mathrm{hrs}$. then turn the stabilizer off (i.e. power absence started).

8- Continue monitoring until partial thawing initiation $(0 \square)$.

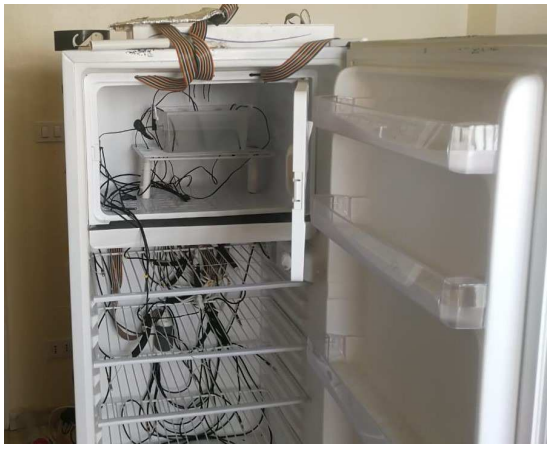

(a) Conventional Refrigerator

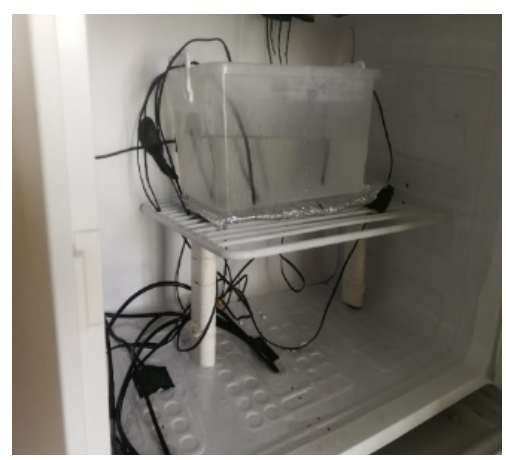

(b) PCM Modefied Refrigerator

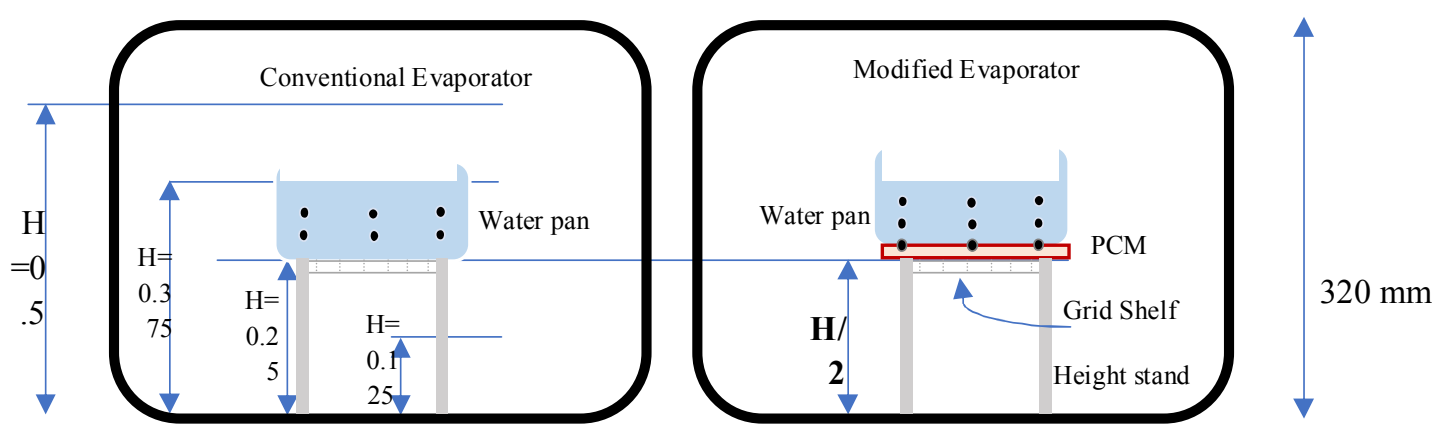

(c) Height positions of thermal loads in the conventional and modified (water pan +PCM) evaporator Cabinets.

Fig. 1 Typical photos and Schematic diagram of refrigerators a) Conventional Refrigerator b) PCM Modefied Refrigerator, and c)Test section schematic.

\subsection{Measuring instruments:}

\subsubsection{Temperature Measuring instruments:}

Measuring Instruments attached to the test rig is classified into three categories: - temperature, power, and mass measurements. Experiments are conducted via compacted data acquisition device (DAQ), established by National Instrument (NI), National Instruments' LabVIEW software reads the data through USB to be displayed and stored by a computer. Temperature values are measured using a fast response negative temperature coefficient thermistor with a 1.33 mm epoxy coated head diameter of each (NTC) thermistor at $25^{\circ} \mathrm{C}$ is $(10 \mathrm{~K} \Omega \pm 1 \%)$. All 
thermistors were already calibrated by temperature kit provider and reverified from $\left(35^{\circ} \mathrm{C}\right)$ to $(-$ $30{ }^{\circ} \mathrm{C}$ ) by using Armfield ${ }^{\mathrm{TM}}$ temperature measurement and calibration device (TH-1) with a resolution of $0.1{ }^{\circ} \mathrm{C}$. Six distributed thermistors are inserted in the water pan to acquire behavior variation of the load. However, three thermistors were attached to the boundary surface of the PCM pouches. Finally, Compartment surrounding ambient air is recorded via ambient air temperature sensors.

\subsubsection{Energy Measuring instruments:}

The Electrical power is fed through a voltage stabilizer (Hemel-1.5 KVA), which maintains refrigerator feeding voltage within (220) Volt. The voltage is measured, monitored, and stored by digital multimeter with an accuracy of $(1 \%+3 \mathrm{cnt}) \mathrm{V}$, provided by (UNI-T). The electricity meter kit includes a current sensor of $( \pm 1 \%)$. The measuring kit is connected to a microcontroller board with USB output to store instantaneous rated ampere.

\subsubsection{Mass measurement instruments:}

Water weight (Thermal Load) is measured by the digital electronic scale of $( \pm 0.5 \%)$ accuracy while the volume is measured by Hydrometer jar (a $500 \mathrm{ml}$ graduated plastic measuring cylinder) with a resolution of $2.0 \mathrm{ml}$. The content of both of Paraffin and mixture pouches used in the experiments was weighted by the mini digital electronic scale of $( \pm 0.3 \%)$ accuracy before pouches fabrication.

\subsection{Data Reduction}

In this study, the PCM incorporation effect on variable water masses placed inside a household refrigerator as well as the energy consumption has been analyzed based on the recorded data and the following calculations: -

The average load temperature is calculated through the following equation (Gin, Farid and Bansal, 2010):

$$
\boldsymbol{T}_{\text {cave }}=\left(\left(\sum_{n=1}^{6} \boldsymbol{T}_{n}\right)-\boldsymbol{T}_{\min }\right) /(\boldsymbol{n}-1)
$$

Where $T_{n}$ is the value of water temperature at each sensor and $T_{m i m}$ is the minimum recorded water temperature of the whole six sensors.

Compressor power, $P$, is evaluated by:

$$
\boldsymbol{P}=\boldsymbol{I} \times \mathrm{V} \times \cos (\varphi)
$$

where $I$ is the instantaneous rated current, $\mathrm{V}$ is the supplied voltage, and $\cos (\varphi)$ is the power factor.

The energy consumed per operation time, $E_{C y c l i c}$, is calculated through

$$
E_{\text {Cyclic }}=I \times V \times \cos (\varphi) x \tau
$$

Where $\tau$ is the total compressor ON time duration throughout 24 hours.

The period factor, $\mathrm{PF}$, which is the ratio of time required for a specific water quantity to reach subzero temperature using PCM to the required time of the same water amount to reach the same temperature without using PCM at power outage.

$$
P F=\tau_{\text {with } P G M} / \tau_{\text {without } P C M}
$$

Where, $\tau_{\text {with PCM }}$ is the time using PCM and $\tau_{\text {without PCM }}$ is the time without using PCM both are measured at the same water temperature. 
The extended recovery time duration, ERT, and recovery gained energy ratio, RGER, are calculated by:

$$
\text { ERT }=\sum \boldsymbol{\tau}_{\text {with PCM }}-\sum \boldsymbol{\tau}_{\text {without PCM }}
$$

RGER $=\left(\begin{array}{lll}E R T & \times P_{\text {without } P C M}\end{array}\right) / E_{\text {cyclic without }} \times 100$

The total energy $\mathrm{T}_{\text {otal }}$ without PCM is calculated as follows:

$\boldsymbol{E}_{\text {total, without PCM }}=\boldsymbol{E}_{\text {cyclic,without PCM }}(\mathbf{1}+\boldsymbol{R G E R})$

Net energy-saving ratio, NESR, revealed from integrating PCM compared to the conventional case is evaluated by:

$$
N E S R=\frac{\left(E_{\text {total,without pCM }}-E_{\text {total,with PCM }}\right)}{E_{\text {total,without pCM }}} \times 100
$$

\subsection{Uncertainty analysis}

Experimental uncertainties are results from several elemental error source, such as instrument condition, instrument calibration, reading errors and others. The following analysis of the relative error for each variable is performed using the present measured data in the experimental work. A precise method of estimating the uncertainty in the experimental result is calculated. The method based on careful specification of the uncertainties in the various primary experimental measurements. The result $\mathrm{F}$ is given as a function of the independent variables $x_{1}, x_{2}, x_{3} \ldots x_{n}$

$$
\mathbf{F}=\mathbf{F}\left(x_{1}, x_{2}, x_{3} \ldots x_{n}\right)
$$

If $\omega_{F}$ is the uncertainty in the result, $\omega_{1}, \omega_{2}, \omega_{3}, \ldots \omega_{n}$ are the uncertainties in the independent variables and these uncertainties in the independent variables are all given with the same odds, then the uncertainty in the result having these odds is given in (J.P. Holman, 2011)

$$
\omega_{F}=\left[\left(\frac{\partial F}{\partial x_{1}}\right)^{2} \omega_{1}^{2}+\left(\frac{\partial F}{\partial x_{2}}\right)^{2} \omega_{2}^{2}+\left(\frac{\partial F}{\partial x_{3}}\right)^{2} \omega_{3}^{2}+\cdots+\left(\frac{\partial F}{\partial x_{n}}\right)^{2} \omega_{n}^{2}\right]^{0.5}
$$

In the present work, there are two types of errors the first is the measured error and the second is the calculated error. The maximum relative error on total energy is $\pm 2.65 \%$.

\section{RESULTS AND DISCUSSION}

In the present study, different PCM types with varied thermal characteristics have been implemented to analyze and compare their influence on thermal product loads of a domestic refrigerator. Firstly, an industrial laboratory prepared C-18, RT-9, Cooler Shock and (c-18+RT-9) are assigned as a PCM mate under the thermal load. Afterwards, conjunction of paired PCMs are tested (i.e. c-18+RT-9). Useful product load parameters such as; cyclic operation temperature regimes, temperature increment trend during power outage process, extended under thawing time (period factor), recovery gained energy ratio, and net energy saving ratio, are investigated.

\subsection{Effect of PCM Conjunction at Different Height Positions}

The previous sections subjected to the effect of single and double PCMs conjunction to various product loads placed on the surface of a free convection evaporator. More examinations are needed to study the effect of PCMs conjunction at different heights inside the evaporator cabinet to be benefited from the whole storage capacity (i.e. not contacted with evaporator cabinet boundaries). Elevation tests are performed to measure the influence of pure convection (i.e. the cooled air inside the cabinet) which represents heat sink instead of the combination of conduction and convection at $(\mathrm{H}=0.0)$, as the modified product is mainly affected by evaporator surface., as the modified product is 
mainly affected by evaporator surface (basic conduction heat sink). A small mechanism consists of (adjustable height stands and grid shelf) is used to change the elevation. The dimension less height of grid shelf is calculated via the equation $\left(\mathrm{H}=\mathrm{h} / \mathrm{h}_{\max }\right)$. Where $\mathrm{h}$ is the height of grid shelf started from the lower evaporator surface, $h_{\max }$ is the maximum height of the evaporator Cabinet (i.e. $320 \mathrm{~mm}$ ).The tested dimension less levels are $(\mathrm{H}=0.125, \mathrm{H}=0.25, \mathrm{H}=0.375$ and $\mathrm{H}=0.5)$.

Figure (2) shows a product temperature variation at different height positions versus time during cyclic operation and subsequent recovery with and without using RT-9 PCM. Seventeen hours of cyclic operation for the heights of $\mathrm{H}=0.125$ and $\mathrm{H}=0.25$ were enough to have a settling temperature oscillation until the end of the whole 24 hours of the reference case. The modified case with the same heights approached a product temperature higher than that of reference case by approximately (1.5 $\square$ ) however, the seventeen hours at the modified case represents a new stage of product decreasing behavior ended by acquiring a product temperature lower than that of reference case by $(1 \square)$ at the end of the 24 hours. At the height of $\mathrm{H}=0.375$ and 0.5 , a similar reference case behavior to that of $\mathrm{H}=0.125$ and $\mathrm{H}=0.25$ however the stabilization time range is shifted by one hour. A significant temperature drop ( $8 \square)$ is acquired at the modified case at the height of $\mathrm{H}=0.5$. The small gap between the top of water pan and the upper surface of the evaporator, also the low thermal conductivity of RT-9 both aided in acquiring a lower temperature than the regular case.

The figures $((2 \mathrm{c})$ to $(2 \mathrm{j}))$ exhibits a comparison between reference cases and equivalent product mass cases modified by RT-9. The recovery time of the modified products exceeds by $0.7,1.4,0.65$ and 1.2 times than the reference case for the product heights of $\mathrm{H}=0.125$, $\mathrm{H}=0.25, \mathrm{H}=0.375$ and $\mathrm{H}=0.5$ respectively. The temperature oscillation behavior of the reference and modified cases are extremely convergent however the minimum approachable temperature of modified product is lower than that of reference case. The conducted tests using RT-9 are repeated using (C-18), figure (3) shows a product temperature variation at different height positions versus time during cyclic operation and subsequent recovery with and without using C-18 PCM. The blast chilling is comprised at $\mathrm{H}=0.125$ and $\mathrm{H}=0.25$ by reaching a products temperature lower than that of the conventional ones by $12{ }^{\circ} \mathrm{C}$ and $7{ }^{\circ} \mathrm{C}$ respectively. Also, the under thawing time of the $\mathrm{C}-18$ modified thermal loads at the planned power absence are prolonged by 0.74 and 0.68 times the regular refrigerator. A poor cyclic operation and recovery performance are accompanied at $\mathrm{H}=0.375$. This may refer to the inferior thermal storage capabilities of $\mathrm{C}-18$ PCM at this position which is aside from the upper and lower evaporator (heat sink). The next height of $(\mathrm{H}=0.5)$ is much closer to the upper evaporator surface which reflects on retaining the blast chilling capabilities but with minor effect on the overall recovery time at power outage. In the case of pairing (RT-9) and (C-18) shown in figure 4, a stabilized temperature behavior at all height levels is demonstrated with a temperature drop ranged from 7 to $8 \square$ than the regular refrigerator. The under-thawing time is increased by $1.28,1.27,2.24$ and 1.83 times that of conventional refrigerator at all consequent height levels respectively. 


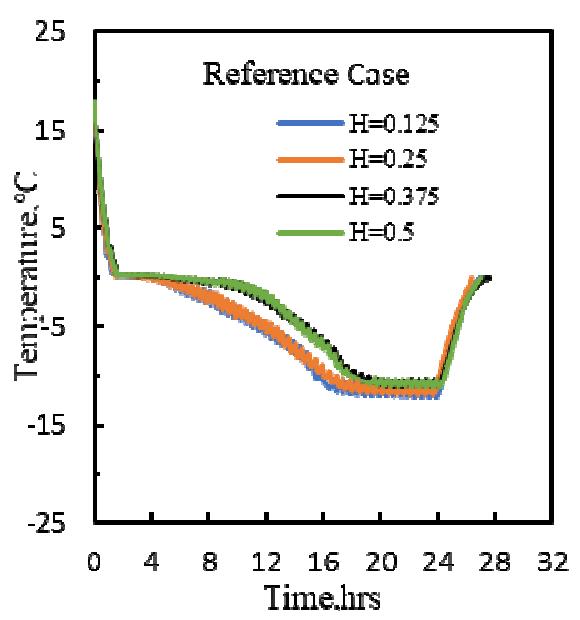

a) Reference case (without) PCM

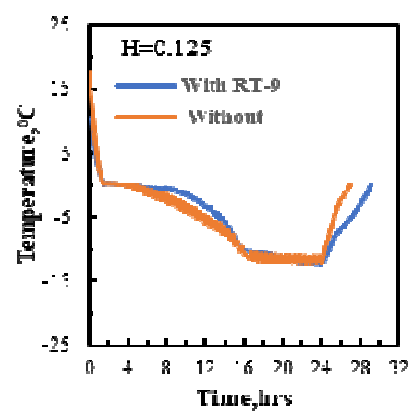

C) Cyclic operation comparison at $\mathrm{H}=\mathbf{0 . 1 2 5}$

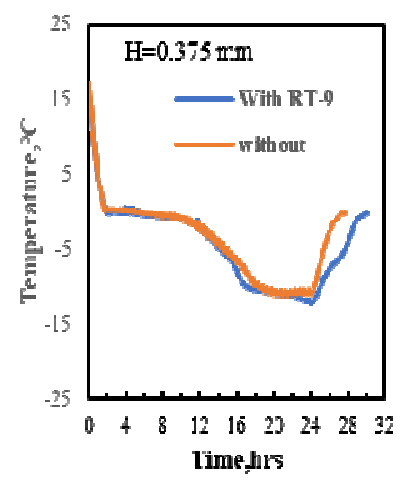

g) Cyclic operation comparison at $\mathbf{H}=\mathbf{0 . 3 7 5}$

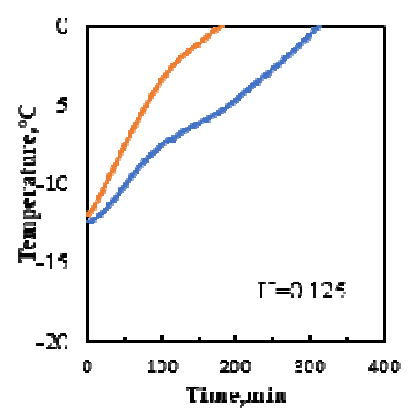

d) Recovery Comparison at $\mathrm{H}=\mathbf{0 . 1 2 5}$

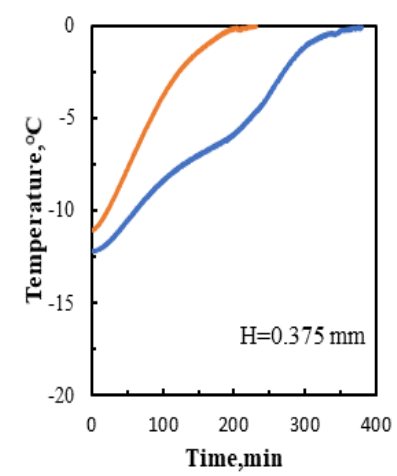

h) Recovery Comparison at $\mathrm{H}=\mathbf{0 . 3 7 5}$

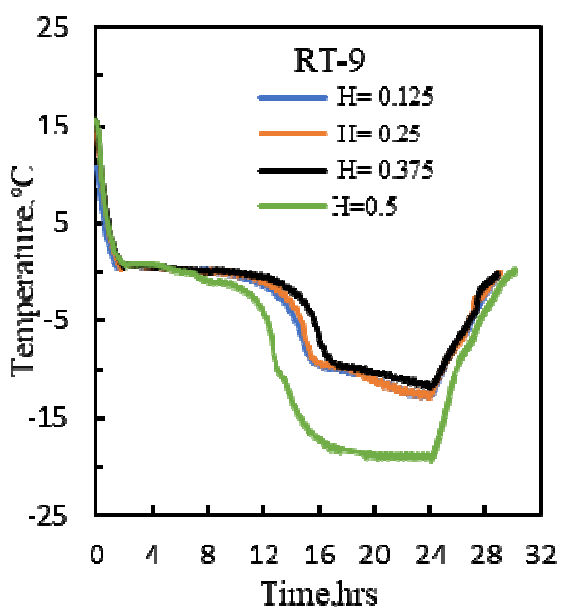

b) Modified case (with RT-9) PCM

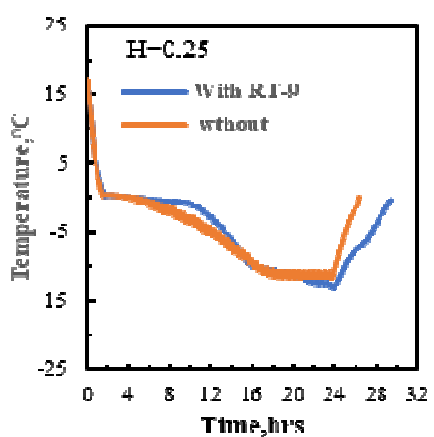

e) Cyclic operation comparison at $\mathbf{H}=\mathbf{0 . 2 5}$

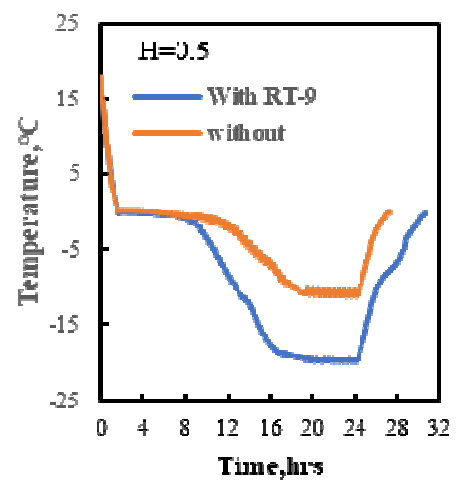

i) Cyclic operation comparison at $\mathrm{H}=\mathbf{0 . 5}$.

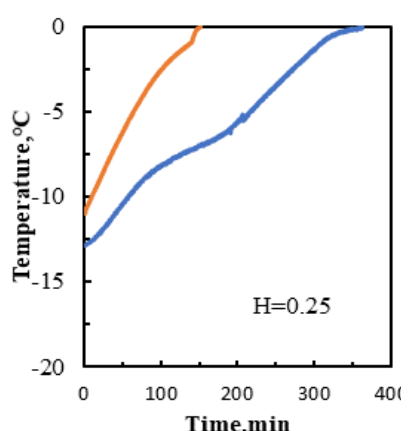

f) Recovery Comparison at $\mathrm{H}=\mathbf{0 . 2 5}$

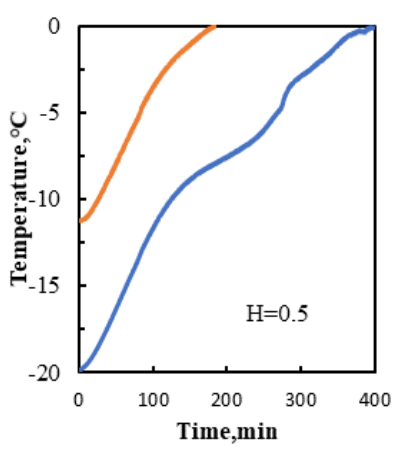

j) Recovery Comparison at $\mathrm{H}=\mathbf{0 . 5}$.

Fig. 2 Temperature variation of the same product load $(\mathrm{m}=1.0 \mathrm{~kg})$ at different Height positions versus time during cyclic operation and subsequent recovery using RT-9 PCM. 
EFFECT OF PCM INTEGRATION AT DIFFERENT HEIGHTS OF REFRIGERATOR CABINET

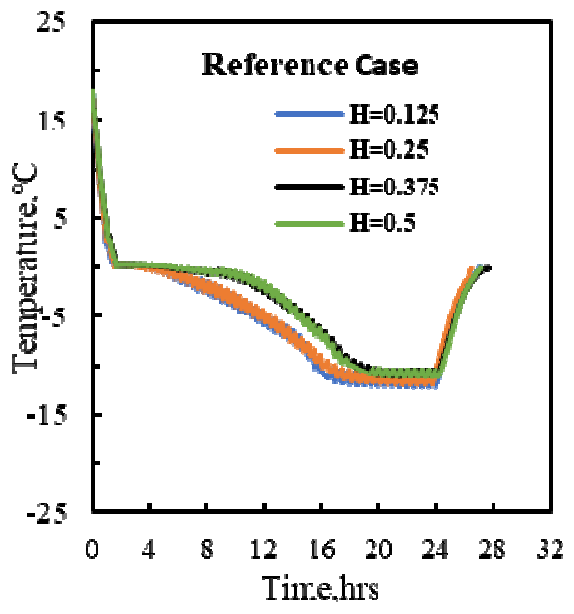

a) Reference case (without) PCM

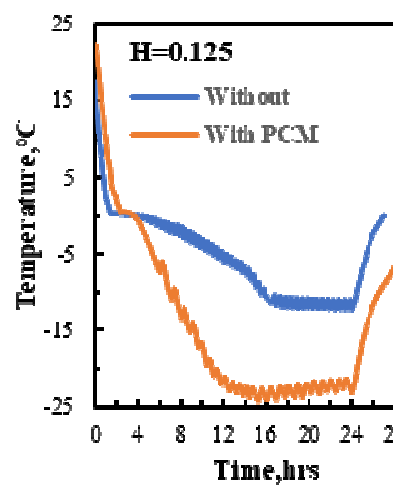

C) Cyclic operation comparison at $\mathrm{H}=\mathbf{0 . 1 2 5}$

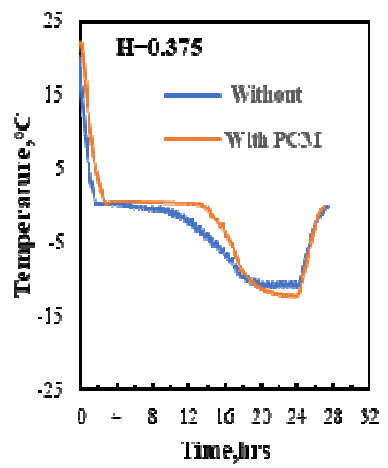

g) Cyclic operation comparison at $\mathbf{H}=\mathbf{0 . 3 7 5}$.

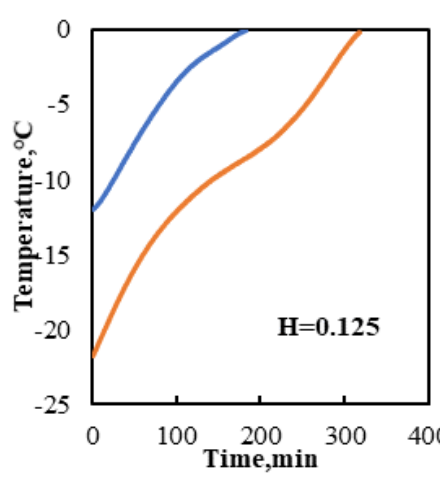

e) Recovery Comparison at $\mathbf{H}=\mathbf{0 . 1 2 5}$

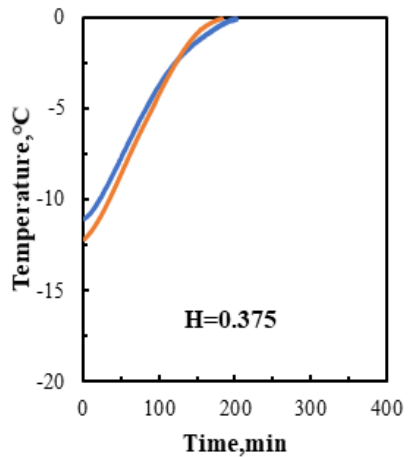

h) Recovery Comparison at $\mathrm{H}=\mathbf{0 . 3 7 5}$.

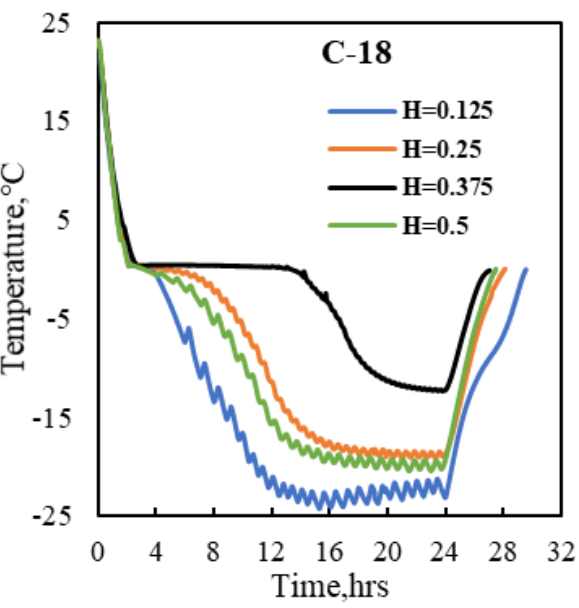

b) Modified case (with C-18) PCM
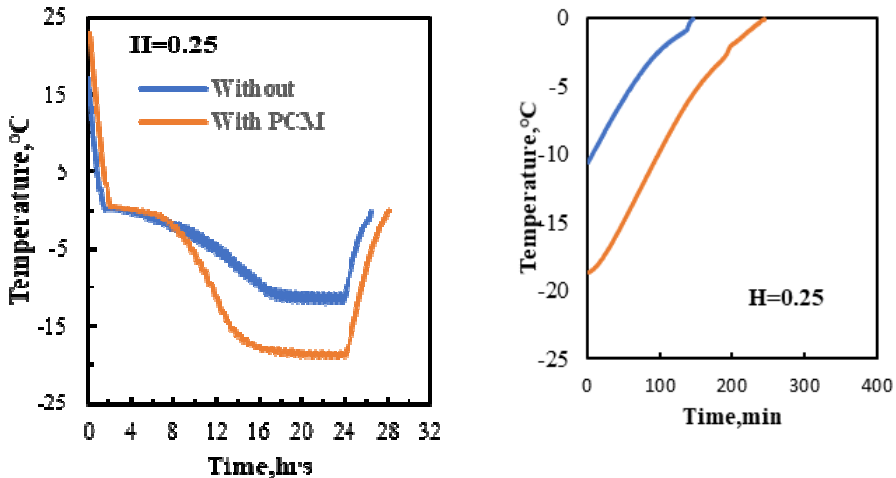

f) Recovery Comparison at $\mathrm{H}=\mathbf{0 . 2 5}$
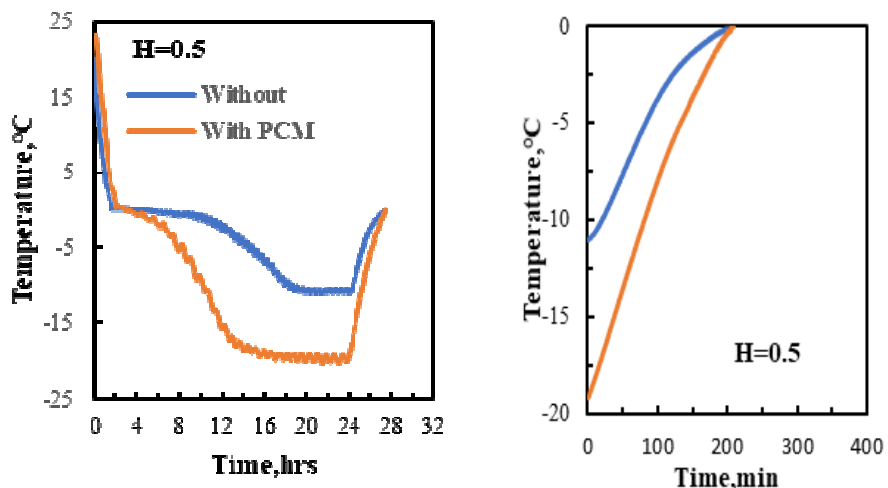

i) Cyclic operation comparison at $\mathbf{H}=\mathbf{0 . 5}$. j) Recovery Comparison at $\mathbf{H}=\mathbf{0 . 5}$.

Fig. 3 Temperature variation of the same product load $(\mathrm{m}=1.0 \mathrm{~kg})$ at different Height positions versus time during cyclic operation and subsequent recovery using RT-9 PCM. 


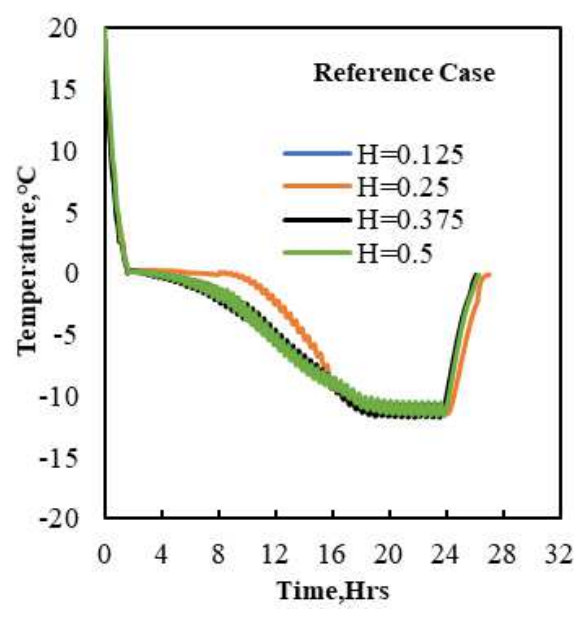

a) Reference case (without) PCM

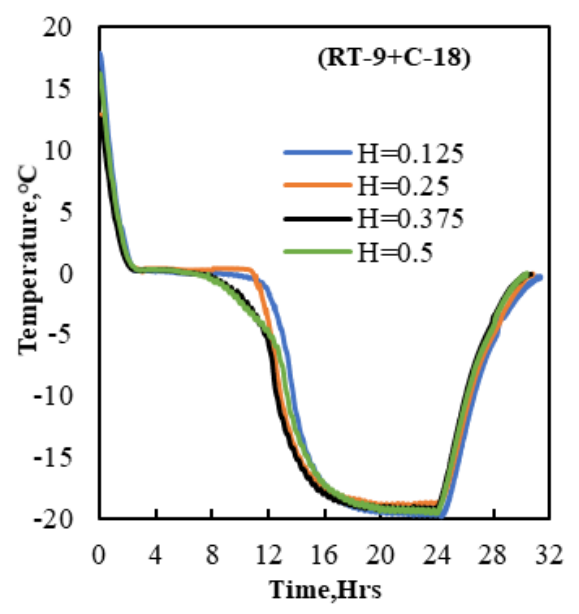

b) Modified case (with RT-9) PCM

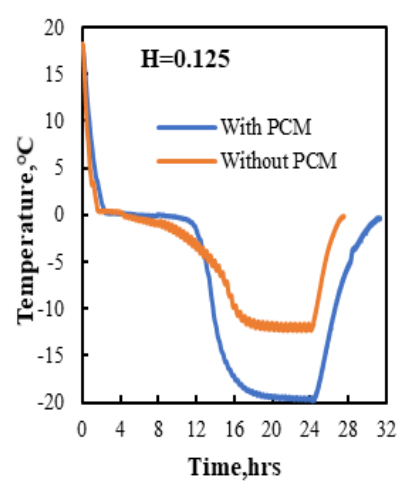

C) Cyclic operation comparison at $\mathrm{H}=0.125$

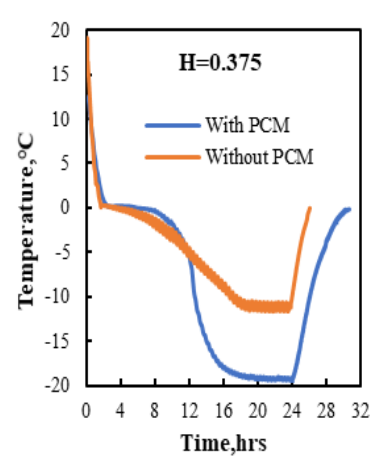

g) Cyclic operation comparison at $\mathrm{H}=0.375$.

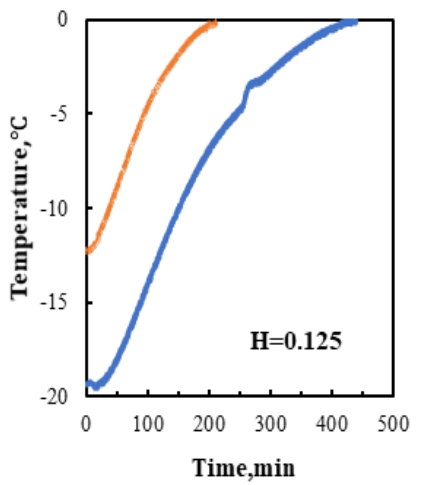

f) Recovery Comparison at $\mathrm{H}=0.125$

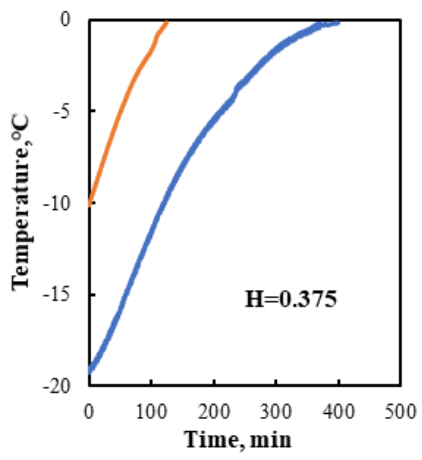

h) Recovery Comparison at $\mathrm{H}=0.375$.

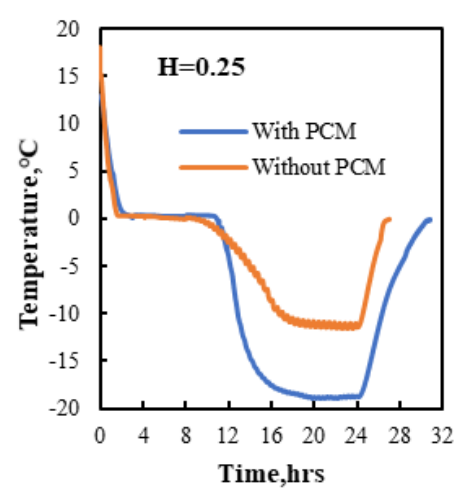

e) Cyclic operation comparison at $\mathrm{H}=0.25$

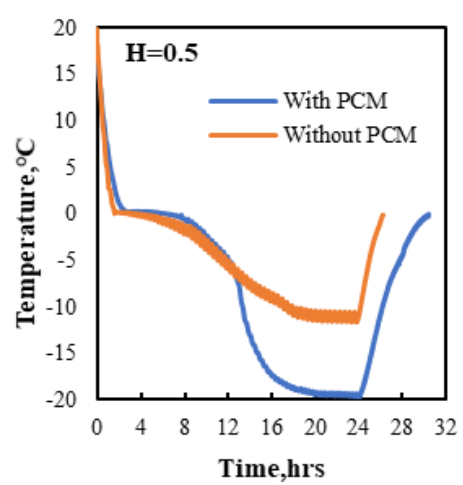

i) Cyclic operation comparison at $\mathrm{H}=0.5$.

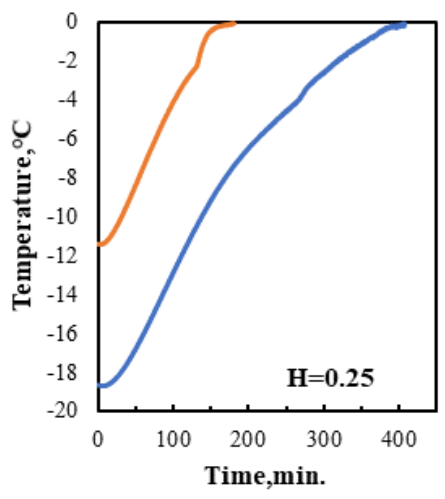

f) Recovery Comparison at $\mathrm{H}=0.25$

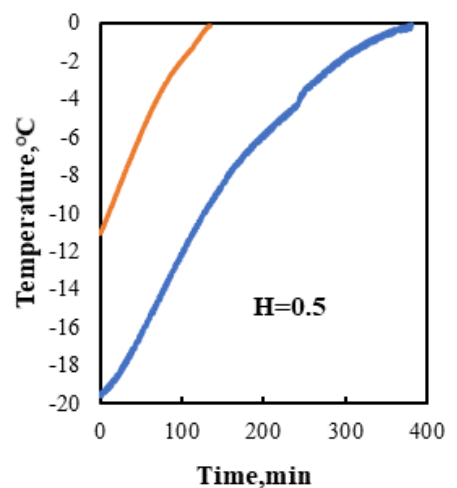

j) Recovery Comparison at $\mathrm{H}=0.5$.

Fig. 4 Temperature variation of the same product load $(\mathrm{PMR}=2.0)$ at different Height positions versus time during cyclic operation and subsequent recovery using RT-9 PCM. 


\subsection{Period Factor PCM Conjunction at Different Height Positions}

Figure (5) shows the relation between period factor versus temperature after power outage using different PCM types assigned to the same product load of $(\mathrm{m}=1.0 \mathrm{~kg})$ at four level positions. The maximum period factor trend is not verified at a definite height position and this may be owing to the difference in the physical properties (as previously mentioned) of each tested PCM.
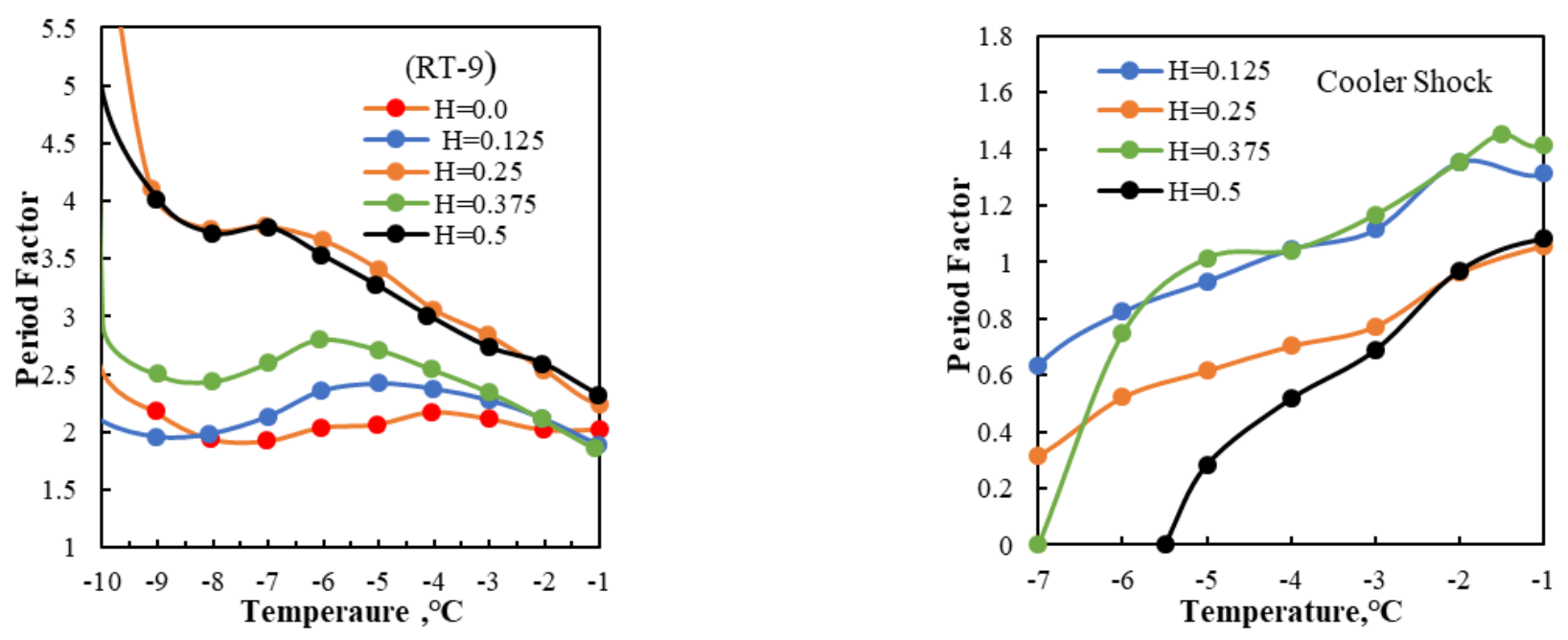

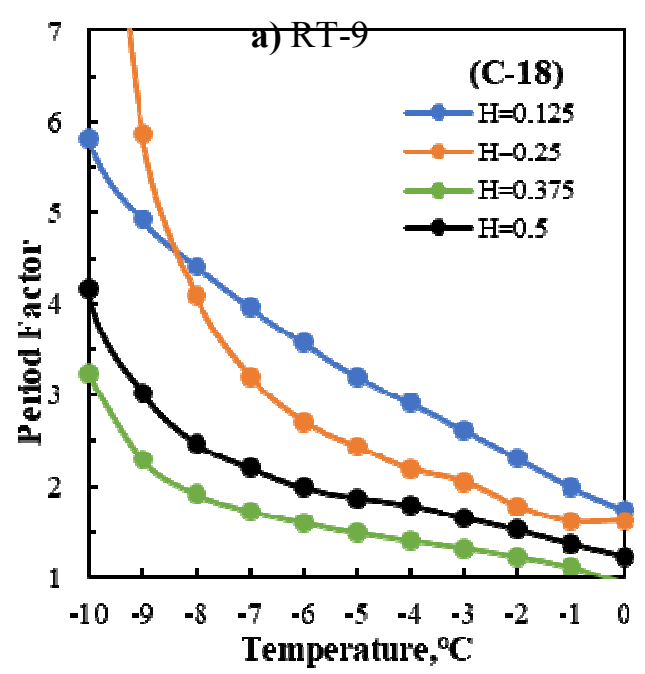

c) $\mathrm{C}-18$

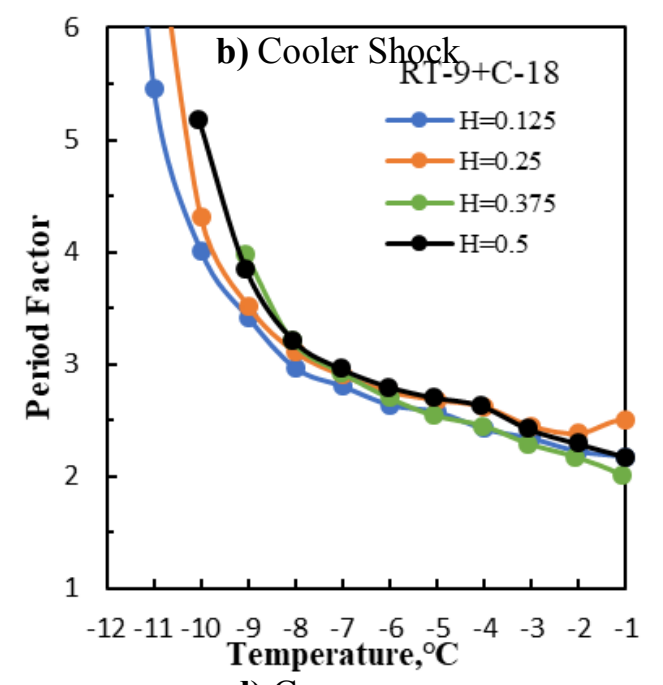

d) Case one

Fig. 5 Period factor against Temperatures using different cases of Coupled PCMs after the power outage.

Figures ((5a) to (5e)) illustrate the period factor regimes using (RT-9, cooler shock, C-18, case one and Mix. A) respectively at different height levels. Figure (5a) shows the period factor at $(\mathrm{H}=0.0, \mathrm{H}=0.125, \mathrm{H}=0.25, \mathrm{H}=0.375$ and $\mathrm{H}=0.5)$ using RT-9. The lowest PF average values are acquired at $\mathrm{H}=0.0$. Rising the height level to $\mathrm{H}=0.125$ enhanced the period factor by approximately $25 \%$. The increment of the period factor values reached its maximum values at the middle of the evaporator cabinet $(\mathrm{H}=0.25)$. A noticeable drop in period factor regime is then acquired at the next height level of $(\mathrm{H}=0.375)$. The period factor at the last position $(\mathrm{H}=0.5)$ is grown up again to an approximately similar values to the that of $(\mathrm{H}=0.25)$. In figure (5b) integrating cooler shock PCM acquires a negligible 
values of period factors at all height levels which is exactly opposite to its behavior at $\mathrm{H}=0.0$.Using $\mathrm{C}-18 \mathrm{PCM}$, as shown in Figure $(5 \mathrm{c})$, reveals a remarkable $\mathrm{PF}$ at $(\mathrm{H}=0.125)$ which is decreased at the further heights of $(\mathrm{H}=0.25$ and $\mathrm{H}=0.375)$.

An increment of the period factor is then acquired at the last position $(\mathrm{H}=0.5)$ presenting a higher value than that of $(\mathrm{H}=0.375)$ but still lower than the values at $(\mathrm{H}=0.125$ and $\mathrm{H}=0.25$ ). Double PCM are represented in the conducted tests using Case One, Figure (5d), at which a convergent values of period factor are acquired at all height levels inside the evaporator cabinet. The integration of Mix. A PCM demonstrates a sequential period factor values started from $\mathrm{H}=0.125$ up to $\mathrm{H}=0.5$. The performance data accompanied with assigning single PCMs (i.e. Cooler shock, RT-9 and C-18) and paired PCMs (i.e. C-18+ RT-9) are made for a different height levels inside the evaporator cabinet are all illustrated at table (6). The recovery gained energy ratio of combining each of the individual PCMs together (i.e. is C-18+ RT-9) is increased by $(24 \%, 15 \%, 21 \%$ and $6 \%)$ for the four different levels respectively than the maximum percentage of each. The maximum net energy saving ratios are demonstrated by using RT-9 at all levels expect at $\mathrm{H}=0.5$ while a negligible energy saving ratio are acquired using paired PCMs. This may refer to the capability of case one products to reach a lower temperature than that the products of RT-9.

Table 6 Performance analysis of the PCM modified and conventional refrigerator at different height Levels

\begin{tabular}{|c|c|c|c|c|c|c|c|c|c|c|c|c|c|c|c|c|}
\hline \multirow{3}{*}{$\begin{array}{c}\text { PCM Type } \\
\text { Height }\end{array}$} & \multicolumn{4}{|c|}{$\begin{array}{c}\text { Recovery gained energy } \\
\text { ratio } \\
\%\end{array}$} & \multicolumn{4}{|c|}{$\begin{array}{c}\text { Net Energy Saving Ratio } \\
\%\end{array}$} & \multicolumn{8}{|c|}{$\underset{\mathrm{C}}{\mathrm{Tmin}}$} \\
\hline & \multirow{2}{*}{$\begin{array}{l}\mathbf{H} \\
=0 \\
.12 \\
5\end{array}$} & \multirow[t]{2}{*}{$\begin{array}{l}H=0 \\
25\end{array}$} & \multirow[t]{2}{*}{$\begin{array}{l}H=0.3 \\
75\end{array}$} & \multirow[t]{2}{*}{$\begin{array}{l}\mathbf{H}=\mathbf{0} . \\
5\end{array}$} & \multirow[t]{2}{*}{$\begin{array}{l}H=0.1 \\
25\end{array}$} & \multirow[t]{2}{*}{$\begin{array}{c}\mathbf{H}=\mathbf{0} \\
25\end{array}$} & \multirow[t]{2}{*}{$\begin{array}{c}H=0.3 \\
75\end{array}$} & \multirow[t]{2}{*}{$\begin{array}{l}\mathbf{H} \\
=\mathbf{0} \\
.5\end{array}$} & \multicolumn{2}{|c|}{$H=0.125$} & \multicolumn{2}{|c|}{$H=0.25$} & \multicolumn{2}{|c|}{$\begin{array}{l}\mathbf{H}=\mathbf{0 . 3 7} \\
\mathbf{5}\end{array}$} & \multicolumn{2}{|c|}{$H=0.5$} \\
\hline & & & & & & & & & M & $\mathbf{R}$ & M & $\mathbf{R}$ & M & $\mathbf{R}$ & M & $\mathbf{R}$ \\
\hline RT-9 & 35 & 48 & 52 & 57 & 17 & 23 & 25 & -4 & -12 & $\begin{array}{c}- \\
12\end{array}$ & $\overline{13}$ & -12 & $\begin{array}{c}- \\
12\end{array}$ & - & $\begin{array}{c}- \\
20\end{array}$ & $\overline{11}$ \\
\hline C-18 & rq & $r v$ & -0 & 13 & -62 & -140 & -190 & $\begin{array}{c}- \\
29\end{array}$ & -24 & $\begin{array}{c}- \\
12\end{array}$ & $\begin{array}{c}- \\
19\end{array}$ & -12 & $\begin{array}{c}- \\
12\end{array}$ & - & $\begin{array}{c}- \\
20\end{array}$ & $\overline{11}$ \\
\hline $\begin{array}{l}\text { Cooler } \\
\text { shock }\end{array}$ & 3 & 3 & 4 & 4 & -13 & -12 & -16 & $\overline{14}$ & -9 & $\overline{12}$ & - & -12 & -7 & - & -6 & $\overline{11}$ \\
\hline $\begin{array}{l}\text { (RT-9+C- } \\
\text { 18) }\end{array}$ & 63 & 63 & 73 & 63 & 3 & 1 & 4 & -1 & -20 & $\begin{array}{c}- \\
12\end{array}$ & $\begin{array}{c}- \\
19\end{array}$ & -12 & $\begin{array}{c}- \\
19 \\
.5\end{array}$ & - & $\overline{20}$ & $\overline{11}$ \\
\hline
\end{tabular}

\section{CONCLUSIONS}

In this study, a single door domestic refrigerator is utilized as a test rig. A comparison is performed between equivalent thermal loads and its PCM modified corresponding's inside the evaporator cabinet at different elevations. Tests were made on water products for full day (i.e. twenty-four hours) including periodic on/off cycles matched with a consequent power down interval. The power absence duration is linked to acquiring a product temperature of $0 \square$ to at which changing in the properties of stored products is inhibited. The newly comprised unit cycle consists of ( 24 hours added to under thawing time). The effect of PCM in is revealed through prolonging under thawing duration compared to the conventional products (i.e. not assigned with PCM). The integration of the PCM is evaluated through a complete charging and discharging cycle. The investigated parameters are; minimum product temperature, period factor, recovery gained energy ratio (R.G.E.R\%) and net energy saving (N.E.S.R\%).

The results of involving different PCMs are concluded as follow: 
- The highest PF values revealed from assigning (RT-9) PCM (for product mass of $\mathrm{m}=1.0 \mathrm{~kg}$ ) for all tested height levels including $\mathrm{H}=0.0$ is acquired at $\mathrm{H}=\cdot r^{\circ}$ and $\mathrm{H}=\cdot \mathrm{r} \times \mathrm{O}$.

- The maximum energy saving ratios using RT-9 modified products are discovered to be at $\mathrm{H}=\cdot$ r 0 (i.e. $23 \%$ ) and $\mathrm{H}=\cdot$. rvo (i.e. $25 \%$ ).

- A similar minimum acquired temperature between conventional products and that modified by RT-9.

- C-18 and cooler shock PCMs comprises a non-positive energy saving ratios at all tested dimensionless heights.

- The maximum energy regains (i.e. from 63 to $73 \%$ ) is acquired by paring RT-9 to $\mathrm{C}-18 \mathrm{PCMs}$ at all the tested heights, which exceeds by (10 to 80\%) than the maximum value of each of them individually.

- Product assigned with parried PCMs (RT-9 and C-18) conducted a minor energy saving value. However, the significant temperature drop verified at all the tested heights (i.e. from 8 to $12 \square$ ) compared to the conventional case.

\section{REFERENCES}

1. Azzouz, K., Leducq, D. and Gobin, D. (2009) 'Enhancing the performance of household refrigerators with latent heat storage: An experimental investigation', International Journal of Refrigeration. Elsevier Ltd and IIR, 32(7), pp. 1634-1644. doi: 10.1016/j.ijrefrig.2009.03.012.

2. Bansal, P., Vineyard, E. and Abdelaziz, O. (2011) 'Advances in household appliances- A review', Applied Thermal Engineering. Elsevier Ltd, 31(17-18), pp. 3748-3760. doi: 10.1016/j.applthermaleng.2011.07.023.

3. Ben-Abdallah, R. et al. (2019) 'Experimental investigation of the use of PCM in an open display cabinet for energy management purposes', Energy Conversion and Management. Elsevier, 198(August), p. 111909. doi: 10.1016/j.enconman.2019.111909.

4. Cheng, W. L. et al. (2011) 'A novel household refrigerator with shape-stabilized PCM (Phase Change Material) heat storage condensers: An experimental investigation', Energy. doi: 10.1016/j.energy.2011.08.050.

5. Cheng, W. L. and Yuan, X. D. (2013) 'Numerical analysis of a novel household refrigerator with shape-stabilized PCM (phase change material) heat storage condensers', Energy. Elsevier Ltd, 59, pp. 265-276. doi: 10.1016/j.energy.2013.06.045.

6. Elarem, R. et al. (2017) 'Performance analysis of a household refrigerator integrating a PCM heat exchanger', Applied Thermal Engineering. Elsevier Ltd, 125, pp. 1320-1333. doi: 10.1016/j.applthermaleng.2017.07.113.

7. Gin, B., Farid, M. M. and Bansal, P. K. (2010) 'Effect of door opening and defrost cycle on a freezer with phase change panels', Energy Conversion and Management. Elsevier Ltd, 51(12), pp. 2698-2706. doi: 10.1016/j.enconman.2010.06.005.

8. Https://www.climator.com/en/pcm-climsel (no date) PCM Provider.

9. https://www.rubitherm.eu/ (no date) PCM Provider.

10. J.P. Holman (2011) Experimental Methods for Engineers. EIGHTH EDI. McGraw-Hill series in mechanical engineering.

11. López-Sabirón, A. M. et al. (2014) 'Environmental profile of latent energy storage materials applied to industrial systems', Science of the Total Environment. Elsevier B.V., 473-474, pp. 565-575. doi: 10.1016/j.scitotenv.2013.12.013.

12. Maiorino, A. et al. (2019) 'The thermal performances of a refrigerator incorporating a phase change material', International Journal of Refrigeration. Elsevier Ltd, 100, pp. 255-264. doi: 10.1016/j.ijrefrig.2019.02.005.

13. Mastani Joybari, M. et al. (2015) 'Heat and cold storage using phase change materials in domestic refrigeration systems: The state-of-the-art review', Energy and Buildings. Elsevier B.V., 106, pp. 111-124. doi: 10.1016/j.enbuild.2015.06.016.

14. Oró, E. et al. (2012) 'Improving thermal performance of freezers using phase change 
materials', International Journal of Refrigeration, 35(4), pp. 984-991. doi: 10.1016/j.ijrefrig.2012.01.004.

15. Oró, Eduard et al. (2012) 'Thermal analysis of a low temperature storage unit using phase change materials without refrigeration system', International Journal of Refrigeration. Elsevier Ltd, 35(6), pp. 1709-1714. doi: 10.1016/j.ijrefrig.2012.05.004.

16. Pirvaram, A., Sadrameli, S. M. and Abdolmaleki, L. (2019) 'Energy management of a household refrigerator using eutectic environmental friendly PCMs in a cascaded condition', Energy. Elsevier Ltd, 181, pp. 321-330. doi: 10.1016/j.energy.2019.05.129.

17. Rahman, R. (2013) 'Performance Improvement of a Domestic Refrigerator Using Phase change Material (PCM)', IOSR Journal of Mechanical and Civil Engineering, 10(4), pp. 08-16. doi: 10.9790/1684-1040816.

18. Rostami, S. et al. (2020) 'A review of melting and freezing processes of PCM/nano-PCM and their application in energy storage', Energy. Elsevier Ltd, 211, p. 118698. doi: 10.1016/j.energy.2020.118698.

19. Sarbu, I. and Dorca, A. (2019) 'Review on heat transfer analysis in thermal energy storage using latent heat storage systems and phase change materials', International Journal of Energy Research, 43(1), pp. 29-64. doi: 10.1002/er.4196.

20. Visek, M. et al. (2014) 'Advanced sequential dual evaporator domestic refrigerator/freezer: System energy optimization', International Journal of Refrigeration. Elsevier Ltd, 43, pp. 71-79. doi: 10.1016/j.ijrefrig.2014.03.001. 